\title{
Narcissism and Universality: The Cinema of Xavier Dolan
}

\author{
Sheida Sheikhha \\ Film and TV School of the Academy of Performing Arts in Prague, Czech Republic
}

\begin{abstract}
A narcissist, as defined by the Merriam-Webster dictionary, is one who is "extremely self-centered with an exaggerated sense of self-importance". Nowadays, narcissism is often studied in regards to contemporary culture, social media, celebrities, and the younger generation. The culmination of these topics can be found in French-Canadian filmmaker and acclaimed "wunderkind" Xavier Dolan. In the twelve years since his directorial debut at the young age of nineteen, Dolan has gone on to direct eight feature films, four of which he has also starred in. Drawing on deeply personal and at times autobiographical themes, it may be difficult to separate Dolan's characters from Dolan the filmmaker. This may be why in multiple reviews and critiques of his films, primarily those he acts in, the concept of "narcissism" has been a recurring theme.

I aim to offer a definition of narcissism and to classify the narcissistic character traits to look for in a study of the four Dolan films in which he acts. I will then analyze the alleged elements of narcissism in the underlying theme, the visual style, and the characteristics of the main characters in order to determine whether these films can rightfully be considered narcissistic or not. Lastly, the critical acclaim and success that Dolan has been faced with begs the question of whether narcissism is in opposition to universality or whether there is a factor of relatability associated with his films, regardless, or maybe because, of the claims of narcissism.
\end{abstract}

Keywords: Narcissism, Xavier Dolan, Celebrity, Millennials, Psychoanalysis

\section{Introduction}

Narcissism can be traced back to Ovid's story of the Greek myth of Narcissus. In mythology, Narcissus was the beautiful man who was wanted by all but would not reciprocate anyone's feelings. As a result and as revenge for the hearts he'd broken, he was cursed to fall in love with his own unattainable reflection. Unable to cope, Narcissus soon succumbed to death thus creating the legend of the vain man so in love with himself that he's unable to live. Over the years, due to the work of psychoanalysts such as Paul Näcke who in 1899 used the term to describe "the attitude of a person who treats his own body in the same way in which the body of a sexual object is ordinarily treated" (Freud 1914, 73) and the subsequent work of Sigmund Freud on this matter, narcissism has stepped away from the myth and become a word used to describe a psychological disorder. Initially, the definition of narcissism dealt with this disorder in a sexual nature as it was said to be the mental condition in which one can only achieve sexual gratification through one's own image. Later, this was expanded to denote a more widespread mental state that includes a gradient of traits including vanity, authority, and superiority.

Celebrities derive their sense of value and success from being liked and seen. Currently, in the digital age, the exposure possibilities are at an all-time high. Due to social media, this new generation of celebrities is no longer confined to movies or TV but instead receives a constant outpouring of praise and criticism from their fanbase, feeding their own sense of self-importance on a daily basis. While this has affected celebrity levels of narcissism with research suggesting that celebrities are significantly more narcissistic than the general population (Young and Pinsky 2006, 469), it has also, in turn, led to something called The Mirror Effect in which this favorable broadcasting of narcissism is affecting new generations and instilling them with an appreciation for narcissism.

At the time of this paper, French-Canadian filmmaker Xavier Dolan has just turned 32. In the 12+ years since he showed up at Cannes with his first feature film - I Killed My Mother (2009), which he wrote, directed, and starred in - he has made 7 other features. Dolan has been criticized for being a narcissist, and has responded to these claims often, going as far as to reply to a particularly negative review with a tweet that said "@THRmovies you can kiss my narcissistic ass." (@XDolan 2013).

I will aim to analyze Dolan's filmography with an outlook at this alleged narcissism and will attempt to understand the different aspects, both thematic and visual, that have come together to brand him as "egomaniacal" and "narcissistic". Dolan's filmography can be split into two categories: films he has only directed, and films he has both directed and acted in. This paper will focus on the latter, analyzing the characters, motifs, and underlying narcissistic elements that come together in each of these films, starting from his first feature I Killed My Mother, all the way to his latest release Matthias and Maxime (2019). Other films studied include Heartbeats (2010) and Tom at the Farm (2013).

It's important to understand narcissism in order to provide a framework by which the films, the characters, and Dolan's approach can be analyzed. Furthermore, it's necessary to have a grasp of narcissism and cinema or, in the broader sense, narcissism and art. This paper will mainly aim to understand how narcissism is reflected in film and the criteria by which a character/person can be dubbed a narcissist. These findings will then be applied to a selection of Dolan's 
filmography to analyze the presence of the concept of narcissism within those films.

\section{Background}

\section{According to the Encyclopedia Britannica:}

Narcissism is characterized by an inflated self-image and addiction to fantasy, by an unusual coolness and composure shaken only when the narcissistic confidence is threatened, and by the tendency to take others for granted or to exploit them (Rhodewalt 2020).

Nowadays, following communal changes in industrial and post-industrial times which brought upon a shift from the collective towards the individual, narcissism is no longer only a clinically recognized disorder but has become a "modern epidemic" brought upon in part by the movement which claimed "that self-esteem was the key to success in life" (Remes 2016). This has led to a more "cultural" definition of narcissism which views it as less of a sexual psychopathic disorder and more as a form of aggravated self-indulgence, surpassing its psychological definition to simply encompass behaviors of self-flattery, perfectionism, and arrogance. According to Professor Jessica Benjamin, Narcissus has now "replaced Oedipus as the myth of our time" (Benjamin 2000, quoted in Tyler 2007, 223).

In a 2013 cover story for Time magazine, Joel Stein dubbed millennials the "Me, Me, Me Generation". According to Pew Research Center, a "millennial" is anyone born between 1981 and 1996 (Dimock 2019). The Time magazine cover story claims that studies show the "incidence of narcissistic personality disorder is nearly three times as high for people in their 20s as for the generation that's now 65 or older" (Stein 2013). The same studies suggest that millennials are fame-obsessed, merely wanting proximity to celebrity and the culture of fame rather than achieving success in another definition of the word. This is a fact that Stein relates to reality television, stating that because millennials grew up watching these shows, "most of which are basically documentaries about narcissists" (Stein 2013), they have been trained for that lifestyle.

Following the Time magazine article, there has been a large number of articles written demonizing millennials as lazy, entitled, and narcissistic. Films about millennials such as Mean Girls (2004) and The Bling Ring (2013) focus on this aspect of millennial culture, showing the characters as shallow stereotypes offering a "veneration of celebrity culture, online addiction, spiritual hollowness" (Clark 2019). Millennial filmmakers documenting their own generation are also not exempt from this classification. Among these filmmakers is French-Canadian Xavier Dolan, who began his career at the young age of nineteen, and has had a bit of a head-start, serving as the prototype for these critiques.
As of April 2021, Dolan, currently aged 32, has amassed a widely successful filmography consisting of 8 feature films, almost all of which have been well received by spectators and critics alike, screening at the most prestigious festivals all across the world. Starting in 2009 with his semi-autobiographical debut I Killed My Mother, Dolan has had a career unlike any other. His first film alone (written when he was 17) gained him 3 awards and a standing ovation at the Cannes Film Festival. I Killed My Mother did more than introduce Dolan as an actor-director, it also introduced him as a queer personality, confident, unapologetic, and fully aware of who he is and what his style is, able to capture "the raw intensity of what it means to be young, passionate and, often, gay" (Rose 2019).

For his second film in 2011, Heartbeats, Dolan again cast himself as one of three lead characters who find themselves caught up in a love triangle. A story of friendship ruined by romantic rivalry, the film allowed Dolan to explore a looser, less dramatic narrative while also providing him with a large number of close-ups, an outlet for his outpour of musings on the basis of love, and an Adonis as a love interest.

In 2012, Dolan took a step back from acting and directed his first big-budget film Laurence Anyways (2012). While the film was not accepted as part of the main competition at Cannes, it still got screened in the Un Certain Regard section and was awarded the Queer Palm; an award Dolan refused to accept, claiming that "the very idea that such ghettoizing awards exist is disgusting" (as quoted by Lafontaine 2019, 12).

In 2013, Dolan returned to acting and received his strongest outcry of "narcissist" when he took on the titular role in his first adaptation, Tom at the Farm. When it premiered at the Venice Film Festival, the film received a twelve-minute standing ovation; However, critic David Rooney of The Hollywood Reporter called the film an "egomaniacal exercise" (Rooney 2013) and Dolan replied to this by infamously claiming they could kiss his "narcissistic ass". Dolan later insisted that had he not been the director, this would not be an issue of discussion, asking whether Woody Allen is "narcissistic for having put himself in front of the camera for all those years, kissing the hottest girls in Hollywood?" (Strombo 2013). The question of narcissistic actor-directors is one I hope to answer later on.

After Tom at the Farm, Dolan did not act in his next three films. It is not clear whether, despite his nonchalant reply, this was a direct result of the negative response he received or not. Whatever the case, his next film, Mommy (2014), is undoubtedly the most liked and well-received film in his repertoire thus far. Earning one of the longest ever standing ovations when it premiered as part of the main competition at Cannes, Mommy is, arguably, the perfect embodiment of Dolan's thoughts and his artistic innovations. The film won the Cesar award and was Canada's submission to the Oscars, though it was not selected by the Academy. 
At this point, Dolan was only 25 and he'd already done and received more accolades than any of his just-starting-out peers. In 2015, he began shooting his 6th film, It's Only the End of the World (2015), another adaptation. This film saw Dolan receive some of his harshest criticism which dubbed that, as a director, he had regressed back into "feeling like the most misunderstood genius who never asked to be born" (Kiang 2016). The blow was felt and Dolan would "later claim the experience had had an effect similar to the trauma of a car accident" (Lafontaine 2019, 12).

Following a break from directing, Dolan returned in 2018 with The Death and Life of John F. Donovan (2018), his first English-language film. The focus of the movie is on John F. Donovan, a celebrity destroyed by the attention given to him. Donovan's story is told through the eyes of a now-grown child actor who used to write letters to him. Dolan himself was a child actor keen on writing letters to actors and when the film premiered at the Toronto International Film Festival, he presented it by reading a letter he had written at the age of eight to Leonardo DiCaprio. In the letter, he introduces himself as an actor who has played in commercials and tells DiCaprio that he is looking forward to playing in one of his movies should he ever "need a young boy in the cast" (@TIFF_Net 2018). The similarities between the character and Dolan go beyond childhood inspiration as there are multiple instances where dialogue between characters can be seen as a means of communication between Dolan and his critics:

Do you feel like you and I come from different planets? [...] Why would you be fighting for truth and I for shit? [...] This is a story about intolerance, this is a story about how a business has been so scared to lose a public it claims illiterate and small-minded that it's basically kept it illiterate and small-minded for decades. This is about us, as a society, [...] you're putting your life in peril for truth and we're strutting around in our first world problems

(The Death and Life of John F. Donovan)

Unlike his previous films, Donovan did not receive glowing reviews and even failed to find a US distributor despite its star-studded cast.

In 2019, Dolan returned to his actor-director roots by premiering at Cannes with Matthias and Maxime which tells the simple story of a queer friendship. This film appears to be a culmination of all the motifs that initially helped him earn his current success, and still, it seemed to coast by almost unnoticed by fans and critics alike.

Dolan claims he spent ten years trying to find himself "through the criticism of others" (Barlow 2019), could it be that for a director who found his voice by digging deep into his personality and being extremely self-aware, the last few years of scrutiny and negative feedback have had a lasting impact on that very self of which he is aware?

\section{Narcissism in the Media}

In a study conducted by Young and Pinsky, in which 200 celebrities - composed of comedians, reality TV stars, musicians, and actors - were asked to complete the Narcissistic Personality Inventory (NPI), the results showed celebrities to be significantly more narcissistic than the general population (Young and Pinsky 2006, 469). The NPI is a research tool used to measure narcissism as a personality trait. In this categorization, reality TV stars ranked highest, followed by comedians, actors, and then musicians. The research also showed no correlation between narcissism and an individual's years of experience in the field, suggesting that those who work in the industry have prior narcissistic tendencies. This research was conducted anonymously and the identity of those 200 celebrities kept secret.

Due to narcissism being viewed as a mental disorder with prejudiced connotations, people are often quick to react defensively when discussing the topic of narcissism within art. Therefore, the relation of art and narcissism has been studied indirectly by analyzing the price of artworks sold at auctions in relation to the artists' narcissism as demonstrated by the size of their signature. In this study, it was found that 'artists' narcissism positively and significantly impacts the auction prices and return on their artworks in the art market" (Zhou 2017, 1). In a broader sense, there is often a correlation felt between narcissism and creativity even though the theories on this topic vary, stating that:

Because creative people spend a great deal of time alone, are often absorbed in their work to the point of obsession, and refuse to conform to social conventions, they are likely to appear narcissistic to others (Barron \& Harrington, 1981). In contrast, some researchers propose that narcissism directly contributes to creativity because narcissists are motivated to generate novel ideas as a way to "stand out" and draw attention to themselves

(Raskin, 1980) (Goncalo et al. 2010, 3).

It is not simply creation that leads to narcissism, but the fact that in art, narcissism "generates the need to encounter and incarnate the ideal" (Giesbrecht and Levin 2012, 10). As discussed by Giesbrecht and Levin in their study of Art in the Offertorium, the idea is not that art is narcissistic but that it doesn't suppress narcissism as much as other fields of work. "Art thinks about narcissism, as opposed to simply disavowing it—or rationalizing it" (Giesbrecht and Levin 2012, ix).

Psychiatry has been a staple of Hollywood stories ever since the beginning, starting with the silent film Dr. Dippy's Sanitarium (1906) which is believed to include the first depiction of a psychiatrist on screen (Gabbard 1999). Mental illness, specifically psychopaths are seen as interesting topics within Hollywood. Even Freud believed that those suffering from disorders such as narcissism stand out within 
stories as their narcissism is attractive "for those who have renounced part of their own narcissism and are in search of object-love". Freud also claimed that our interest in criminals in literature stems from "the narcissistic consistency with which they manage to keep away from their ego anything that would diminish it" (Freud 1914, 89).

The majority of films featuring narcissistic characters tend to opt for those on the extreme end of the sociopathic spectrum, engaging in homicidal activities and physical acts of violence. These are the traits of narcissism that are best transferred to the visual medium (Milstead 2018). Among these films, perhaps one of the most prominent would be American Psycho (2000), in which the main character, a serial killer, displays many of the tell-tale signs of a person with Narcissism Personality Disorder. Similarly, films such as Gone Girl (2014) and The Talented Mr. Ripley (1999) also depict narcissists as extremely cold, calculating, and smart characters, controlling and deceiving others. However, it's not only murder and violence that narcissism in mainstream cinema is linked to, it's also excess and luxury as depicted in inspired-by-real-life movies such as Catch Me If You Can (2003) and The Wolf of Wall Street (2014). In these films, the narcissist is shown to be extremely successful and, again, able to manipulate and deceive others, though through less bloody means.

On the less extreme side are films with "self-absorbed, unpleasant and yet curiously watchable characters" (Lyttelton 2014). Some of these types of characters include depictions of artists, filmmakers, or real-life successes, as seen in The Life Aquatic with Steve Zissou (2005) and The Social Network (2010). These characters are less focused on the luxurious and over-dramatic aspect of narcissism, they're real people, albeit more successful and thus more self-obsessed than the general public. One step below them is the narcissistic parasite which includes average, egocentric, and often self-victimizing people. The most prominent example of this would be found in the work of notoriously narcissistic director Woody Allen, such as Annie Hall (1977). While Dolan's characters aren't on any list (that l've found), as we'll come to see later, they do tend to fall under the latter, less extreme category.

\section{Xavier Dolan in the Media}

The topic of filmmakers and narcissism is not a new one. A glance at film history shows that a great deal of directors were deemed arrogant, demanding, and occasionally narcissistic. This is especially true of auteur directors, as they are seen as the sole creator of their films and constantly drawing on their own lives for their stories. "Truffaut is alleged to have said that one repeatedly makes the same film, which is always about oneself" (Gabbard and Gabbard 1999, 248). What, then, can be said of the auteur who also positions himself in front of the camera? "Whenever an actor directs his own performance (and it is almost invariably a "he"), there is the risk that a film will morph into a vanity project" (Gilbey 2019). An example would be Woody Allen who, in the 1997 film Deconstructing Harry, plays a successful novelist who has ruined his personal life. Allen is quoted as saying he's sure the audience will think he is the character, "But they think that of everything I do. I don't care. That is one of the curses or the blessings of what I do. That is why they come or why they stay away" (quoted by Hirschberg 1997). In fact, Allen is banking on his own self-obsession and inviting the audience to join him (Gabbard and Gabbard 1999, 248-249).

As for Dolan, his comparisons to Allen extend beyond his own self-proclamation. In an article for The Guardian, Tom Seymour brands Dolan "a millennial Woody Allen" pouring "his vanity, his insecurity and his bravado into his films" (Seymour 2015). Dolan has addressed the criticism against him multiple times, claiming he reads all of the reviews written about him. While he insists he no longer feels insecure, he still says:

I doubt everything: my ideas, my choices, my behaviour, my decisions. I just don't doubt my ability to achieve things if I don't succumb to the fear of displeasing people - or the obsession with pleasing them. (as quoted by Seymour 2015)

In an interview with The New York Times, he once mentioned that he believes people dislike him as he has a "big mouth" and they see him as "a narcissistic brat"; a matter that doesn't seem to faze Dolan as he claims he has always spoken his mind and been true to himself (Higgins 2018). Although he claims to be unaffected by criticism, he has mentioned that he has "benched" himself from acting in roles in his own films that he finds interesting. In an interview with The Guardian, he was quoted as saying he wishes he had parts as generous as that of Anne Duval, or the main character in Mommy, or Antoine in It's Only the End of the World but that he feels he cannot give such roles to himself as he would be called "narcissistic" which he believes is people's "favorite word" for him (Bradshaw 2017).

As mentioned, there is a certain amount of prejudice linked to actor-directors. While many cases of this seem to be established actors trying their hand behind the camera and hoping to move to the next step as they foray into directing, with Dolan, his preference seems to lie with acting over directing. Acting allows him to express himself and directing is his way of ensuring this happens within the type of films he wishes to be involved in. He has mentioned that he's hoping to focus more on acting in his 30 s, calling it "more rewarding and more liberating" than directing (Barlow 2019). In an interview with IndieWire, prior to filming Matthias and Maxime, he expressed a wish to focus on acting, saying: 
I've sacrificed acting for directing, and I just can't do that anymore. I work so hard with actors, and give them my all. I enjoy watching them acting, and acting through them, and being inspired by them, but it's not enough. At some point, I grow envious of not being able to perform my own ideas myself, and act with great actors too. [...] When an actor doesn't thrive, he withers, and as much as directing is interesting, it is not liberating. Only acting is, to me. You find a lot of actors wanting to direct because they crave control. I want to relinquish it. (as quoted by O'Falt 2016)

Dolan has not shied away from commenting on or, at times, basking in the "impish and arrogant" image that's been painted of him. Certainly, the acclaim he received at a young age, comparisons to the likes of Alfred Hitchcock and Woody Allen, may have helped further this view. Following the success of Mommy, when he was compared to Orson Welles who had made Citizen Kane (1941) at 25, Dolan replied by jokingly stating that Welles was "lazy" and a "late bloomer" (Mesley 2014). Speaking of Jean-Luc Godard and the comparisons drawn between his film Heartbeats and Godard's Contempt (1963), he mentioned that he's never seen it and "now that l've heard Godard has said [negative] things about Mommy, I will never see it" (McGovern 2015). While he claims to appreciate negative feedback in that it gives him room to grow, he has also been quick to fire back at what he believes to be unfair criticism.

Perhaps the most infamous of these instances has been a particularly scathing review of Tom at the Farm by David Rooney of The Hollywood Reporter who stated that Dolan has "an extraordinary eye" which "spends considerable time trained on the French-Canadian writer-director himself" (Rooney 2013). The review then goes on to claim that "CUT TO EXTREME CLOSEUP OF ME appears to be the predominant script note" resulting in the film becoming about "auteurial self-adulation". The film is claimed to be difficult to take seriously as "scene after scene explores the director's face with such swooning intoxication. Shots of Tom are held and held and then held some more". And at last, the suggestion is made to Dolan that he spend less time "fetishizing his own image and more on building credible character dynamics and psychological complexity" (Rooney 2013). In an interview with George Stroumboulopoulos, Dolan addressed this review, claiming that "It's called Tom at the Farm. I'm Tom. At the farm. So once we're at the farm, I will be in front of the camera. That's one thing we know about the movie" (Strombo 2013). In another interview, he later clarified that he believes there "are as many close-ups of everybody else in the film as there are of me," and that this review "was a review of my personality, not of my work" (McGovern 2015).

\section{Discussion}

There is endless literature on narcissism and how to identify and cope with it. It is said that there are degrees to narcissism, it is not a disorder one either has or doesn't but rather "a particular constellation of personality traits"; of which there are seven prominent features to look for: "authority, entitlement, exhibitionism, exploitativeness, self-sufficiency, superiority, and vanity" (Pinsky and Young 2009, 89).

To have a clearer understanding of what to focus on in my analysis of Dolan's characters, the following checklist, provided by the American Psychiatric Association's DSM-5, Diagnostic and Statistical Manual of Mental Disorders, Fifth Edition, will be taken into consideration. In order for a diagnosis to be made, a person must meet five of the following nine characteristics:

\section{A grandiose sense of self-importance}

2. A preoccupation with fantasies of unlimited success, power, brilliance, beauty, or ideal love

3. A belief that he or she is special and unique and can only be understood by, or should associate with, other special or high-status people or institutions

4. A need for excessive admiration

5. A sense of entitlement

6. Interpersonally exploitive behavior

7. A lack of empathy

8. Envy of other people or a belief that others are envious of him or her

9. A demonstration of arrogant and haughty behaviors or attitudes

In order to analyze claims of narcissism against Dolan, I will discuss Dolan's films as an actor-director in terms of theme, style, and character traits; studying whether the underlying theme of the film contains elements of narcissism or self-obsession, whether the style favors Dolan's close-ups or screen time over those of others, and whether the characters themselves - often seen as self-inserts of the director exhibit elements of narcissism or not.

\section{Killed My Mother}

Dolan has said that his first feature film was semi-autobiographical. In fact, the mother/son conflict at the root of this film is present in almost all of Dolan's other work as well. There are elements put into the character of Hubert (played by Dolan) that confer with what is known about his personal life. For example, the instance in which Hubert's mother claims he was obsessed with DiCaprio in Titanic and that he wrote him a letter is an actual Dolan memory as previously mentioned in this paper. Other self-reflective elements of this story include the Quebec setting which is prevalent in the majority of Dolan's films and the queer characters, also a staple of his personal life and the stories he is known for. Thematically, this may be among Dolan's most narcissistic films due to the simple inherent narcissism of a nineteen-year-old with no prior experience writing, directing, and starring in a movie about his own life. 
Stylistically, as the film begins and introduces the character of Hubert, we are faced with extreme close-ups of his face, particularly his eyes, in black and white, as he addresses the camera directly, offering us an insight into his thoughts and his feelings towards his mother. These shots present the character in a favorable light, bringing us close to him and separating him from other sixteen-year-old characters in movies simply by virtue of the way he speaks and voices his thoughts. Later on in the film, there is a series of close-ups on a black and white poster of James Dean closely resembling the black and white sequences in the film and subconsciously tying Dolan to Dean in this visual aspect.

Outside of these black and white scenes, when the story officially begins, we are met with Hubert and his mother at the breakfast table. It may be worth noting that in this introductory scene, Hubert is shirtless, a fact that is repeated by other Dolan characters in their introductions later on. In fact, though not much of consequence, I Killed My Mother features a total of seven shirtless scenes which, if nothing else, highlights Dolan's comfort in front of the camera and his apparent openness in baring who he is and exposing all for the film.

On the other hand, the antagonist, i.e. the mother, is introduced in an extremely unfavorable light with an extreme close-up of her mouth showing her messily eating an orange and a cream cheese sandwich. This is then followed by a shot of her applying makeup while driving. Both actions are seen as somewhat off-putting by Hubert and the viewer alike. We are meant to understand his frustration and to feel his disconnect in regards to his mother. In fact, despite the fact that Hubert is constantly yelling at his mother throughout the film, we are rarely made to side with her as he is almost always shown to be in the right.

While it is true that the film focuses on Dolan, the majority of the shots in the film are actually two-shots featuring Hubert with either his mother, his boyfriend, or his teacher, emphasizing the story through his relationship with others rather than purely focusing on him and his close-ups. It could also be said that the style of the film itself is made up of close-ups, whether they be of people or of objects, abstract shots of butterflies, artwork, etc.

Characteristically, Hubert is a temperamental artist, he is both a skilled painter as confirmed when his boyfriend's mother comments on how impressive his art is and commissions him, and also skilled at writing and poetry, as confirmed by his teacher submitting his work to a competition on his behalf. Both of these skills are apparently things that come naturally to Hubert as we do not see him working on them. His character also finds himself different from others his age and refers to his classmates as "morons". He is self-proclaimed to be different:
When people say "particular", they lack the intelligence to understand "difference". Or to appreciate it. Or to have the guts to admit they hate it. (I Killed My Mother)

Hubert showcases a sense of self-importance and a belief that he is special. He also appears to be entitled, occasionally arrogant, and envious towards his boyfriend for having a more understanding mother. While on paper Hubert appears to have all the tell-tale signs of a narcissist, it is worth noting that he is also a troubled teenager and, at least in part, a lot of these traits also coincide with that aspect of his character.

\section{Heartbeats}

Thematically, Heartbeats takes a step away from the autobiographical and offers us a love triangle between Dolan's character Francis, his best friend Marie, and the object of both of their attractions: Nico. Whereas the previous film was about the rocky relationship between a mother and a son, with the son's sexuality, or rather his hiding it, being one point of conflict, this film is entirely focused on the concept of relationships and sexuality. Its main form of conflict is between a girl and a boy vying for the affection of the same guy and the struggle in seeing which sexuality he leans towards. This main storyline is often intercut with seemingly unrelated talking heads of people describing their relationships and their own faux pas. The film also briefly touches upon the concept of celebrities as sex symbols when a character asks Marie if she ever thinks of movie stars during sex; dropping the names of Marlon Brando, Paul Newman, and James Dean. Another point of reference to the visual unattainability of the celebrity comes from Dolan styling himself as James Dean while Marie styles herself as Audrey Hepburn upon hearing of Nico's love for the actress.

Stylistically, Heartbeats starts in the same vein with a close-up of someone speaking; though this time, it's not Dolan that begins the film but rather the seemingly unrelated talking heads. The first main character introduced is Nico, the love interest. The focus is on his every move as though a spotlight is placed upon him. We then see the person that these apparent points of view belong to: Marie, and finally, behind her, stealing a glance, we catch a glimpse of Francis. He is first seen hidden behind Marie, and then from behind as we are shown only the back of his head. Though the introduction focuses on flattering close-ups of $\mathrm{Nico}$, it is Francis that is shrouded in mystery, hidden from us, and thus our main point of interest as we wish to see his face.

When we do finally see him, he is shirtless, just like Dolan's introduction in his first film. This film also has a similar amount of shirtless scenes, continuing Dolan's comfort in front of the camera and in line with the narcissistic element of exhibitionism. 
Though this film is marketed as a triangle with all three characters getting an equal part of the poster, the character we follow and relate to most is mainly Francis as he's shown in the most favorable light. We feel for his pining and see Marie as his competition, the person trying too hard to usurp his claim to the love interest; she even goes so far as to backtalk him when he is not there. When given the chance, Francis does not do the same; instead, he makes way for her and Nico to go to the cinema alone together.

Stylistically, this film takes a step away from the two-shot and mainly focuses on each character in close-ups as an artistic expression of the disconnect between the characters. Of the three main roles, Francis has the longest screen time and the most amount of close-ups. While the film is filled with expressions of beauty aimed at Nico, Francis also receives his fair share of compliments, mainly from Nico's mother calling him "a twinkie", "a cutie", and "a heartbreaker".

This whole film is about beauty and vanity. The characters spend a lot of time in front of mirrors, with multiple montage sequences showing them trying their utmost in order to seduce Nico. Marie's character is often shown favoring elegance over comfort in clear contrast to Francis' more effortless look. While this may be seen in line with the narcissism viewed in Dolan's image of self, it is also in line with the different societal beauty expectations placed upon women and men. Of the character traits of a narcissist, Francis and Marie do not seem to have any besides a preoccupation with fantasies of ideal love. As for Nico, since we see him through their affectionate eyes and never get a glimpse into who he is on his own, he appears to be flawless, up until the very end.

Heartbeats is also a film about rejection, this is Dolan stepping away from his image as a heartthrob and main character, talking more about his insecurities. In the beginning, we see marks on the bathroom wall and, at the end, we come to understand that these are marks to keep a tab of every time Francis is rejected. Ultimately however, it is not Francis that gets rejected, it is his sexuality. "How could you think I was gay?" Nico says upon hearing Francis' confession. The rejection does not lie in anything Francis has control over.

\section{Tom at the Farm}

In his first adaptation, Dolan tries his hand at a psychological thriller instead of his usual social dramas. Tom at the Farm tells the story of Tom who, after the death of his boyfriend, goes to attend his funeral not knowing that the boyfriend's family was unaware of his sexuality. The story deals with the topic of homophobia and self-loathing. At multiple times during the film, Tom claims that he is "worthless" and deserving of the hardship that befalls him. The ever-present theme of a mother and son conflict is available by proxy through the relationship that Tom's deceased boyfriend and his brother seem to have with their mother. A relationship that appears to be the root of both of their problems.
Tom, Dolan's character and the titular protagonist of the film, is introduced through extreme close-ups, as in the previous two films. We first see his cigarette, and the back of his head as he is driving. We see Dolan, premiering a brand new shockingly blonde hairstyle, first through his profile, then an extreme close-up of his eyes behind glasses, and then finally through the front window of the car. When he exits the car, his back is still to us for some time, depriving us of a proper close-up of him until we finally see this new Dolan, a complete step away from his usual characters. No longer playing a variation of himself, he is now Tom.

While it's true that Tom is the only character seen in the first 9 minutes of the film and it isn't until minute 12 that another character (the mother) gets a close-up, the opening shots used contain as many sweeping wide shots of the landscape and the house as they do close-ups of Tom. It is my opinion that critiques of this film being narcissistic simply for featuring too many close-ups of Tom are unjust as the film is meant to convey the feeling of loneliness and his fear of stepping into an unknown world. There are a great many wide shots signifying the emptiness and vastness of the house and creating an eerie atmosphere. We rarely see the main three characters in a two-shot or three-shot, instead always viewing them in an extreme wide shot or one by one. Whatever close-ups there exist are used diligently to showcase their weirdness and each character's isolation. This is also the first of Dolan's films to offer a less than aesthetically beautiful image of its characters; even the so-called love interest/antagonist in the film is more frightening than appealing.

Characteristically speaking, though Dolan is noticeably less shirtless in this film than in the others, there are other small elements of narcissism within the characters here. In the one flashback scene of the film where, during his boyfriend's funeral, Tom remembers singing with him at a karaoke bar, it's himself he remembers, and not the boyfriend. Overall, the character of Tom is more burdened with masochism and with the belief that he deserves to be mistreated. After a certain point in the film, he even speaks less, allowing others to speak instead of him as he loses bits and pieces of who he is, first his belongings and then his words. If there is a narcissistic character, it would be that of the brother Francis who lacks empathy, shows arrogance, and seems entitled, or even the now-dead boyfriend who was, as we come to find, lying to and manipulating Tom.

\section{Matthias and Maxime}

In his most recent film, Dolan tries to step away entirely from his looks, making himself considerably less attractive by choosing to give his character a visible birthmark, covering half of his face. This is a film about friendship and acceptance. Dolan draws a parallel between his character's visual imperfections and his own inner ones saying he also has a "mark that's bleeding, a sort of wound. It's about my insecurities or my fears, which my friends in the past years have made 
me forget just by their presence" (Barlow 2019). While visually the character of Maxime is different from the typical Dolan character, thematically, he is going through the same kind of struggles with his mother and his aim in life. Matthias, the love interest, is the one having a crisis of sexuality, another topic prevalent in Dolan's films.

The movie begins with the two of them running on a treadmill at the gym. In the first shot we see feet, the second, we see Maxime in the foreground out of focus with Matthias in the background in focus. When we do see Maxime, in the reverse of this shot, it's the marked side of his face in focus. The close-up we later see of him in the car focuses on his birthmark again. All throughout the film, Maxime's shots are almost always pointed at this side of his face, we rarely ever see him frontal. He is the birthmark, a character hiding behind this "irregularity" of his face. Though the birthmark does not play a major role in the story of the film, it does in how Dolan, fresh off the comments regarding his narcissism, chooses to depict himself in his film. It's not just in how he looks, it is his posture, how he stands, how he acts and portrays his character, he is slumped, made to look smaller, even "frumpy" at times. In clear contrast to the nineteen-year-old who was often shown in a favorable light, he is stripping his image of all that makes him who he is, choosing to direct your attention towards the acting.

Matthias, his love interest, is successful, polished, "handsome". He is the one with multiple shirtless scenes in this movie, with the gaze of the lens aimed fully on him, we see him swimming, dressing and being observed.

An interesting aspect about this film is the presence of a filmmaking student whom Matthias says "will annoy the fuck out of us with that [film she's making for school]". Her character is shown as being extremely stupid and "Americanized" so to speak, talking with an anglified accent and an overindulgent use of the word "like" in her speech. It's said her short film is about the question of "who am I?" but then when it is shown it doesn't appear to be anything but random shots. Regardless, it's highly praised and has the other characters all being critics by over-analyzing the colors and shots. If there is a narcissistic character in this film, it is definitely this aspiring filmmaker with her grandiose sense of self-importance and need for admiration. Is this character a self-insert of how Dolan viewed himself at that age or how he feels he is viewed by others?

In a climactic scene in the film, Dolan's character punches a mirror, shattering the "illusion" of himself. It's one of the first times we very clearly see his face in its entirety, in a proper close-up right before he looks away, he breaks himself quickly, unable to face who he is. And yet, in the end, it is this character, flaws and all, that manages to "score" the handsome main love interest. It is in this film, finally, that his character gets who he wants and maybe, just maybe, lives happily ever after.

\section{Conclusion}

Narcissism and art have always gone hand in hand, with creativity and art in a constant state of give and take. Nowadays especially, it can be said that narcissism is prevailing, a modern epidemic that many feel, relate, and even aspire to. Despite narcissism's negative connotations, this new generation of acceptance and self-love, brought on by social media, the self-esteem movement, and the global reach and fame of celebrities, is viewing narcissism as a desirable trait worthy of admiration.

As discussed through the study of the four Dolan films analyzed in this paper, there are certainly attributes, both stylistically and thematically, that can lead to his films, especially his earlier ones, being deemed narcissistic. Hubert, the semi-autobiographical character in his first feature, has almost all of the telltale signs of one suffering from Narcissistic Personality Disorder (and those of a teenager). There's no arguing that his characters are often introduced favorably, receiving the majority of the screen time and a large number of close-ups, or that the topics addressed are taken from Dolan's own life and experiences. All things considered, is the criticism of Dolan's films as narcissistic works of art valid? Maybe not.

The widespread appeal and success of Xavier Dolan begs the question of not whether he is a narcissist or not, but whether his narcissism is his selling point. My aim was not to diagnose him. After all, Dolan himself has said that he is "interested in reviews, not diagnosis" (Strombo 2013). My aim was to see whether this so-called "narcissism" is not the very thing that has led to his universal success amongst a generation that appreciates honesty and self-acceptance. Furthermore, as all auteur actor-directors are slightly narcissistic, isn't the thing that separates Dolan from those not receiving criticism the mere fact that he is more open about this aspect of his personality? It could also have something to do with the fact that Dolan is young and conventionally handsome, as compared to those older auteurs. Every new generation of directors brings with it a certain characteristic. It is unreasonable to expect millennial directors to have the same attitude as their predecessors. Perhaps Dolan, dropping out of college after one week and going straight to creating features, simply started earlier than the rest and, as such, faced the brunt of the criticism before his peers caught up. There is a whole generation of millennial filmmakers coming, each set to be unapologetically narcissistic.

\section{Bibliography}

@TIFF_NET “Xavier Dolan introduced THE DEATH AND LIFE OF JOHN F. DONOVAN at \#TIFF18 by reading a letter he wrote at the age of 9 to Leonardo DiCaprio. Eat your heart out, internet: [image]" Twitter, 11 Sep 2018, 4:09 a.m. https://twitter.com/tiff_net/status/1039335093884600321 Last accessed 04/04/2021 
@XDolan “@THRmovies you can kiss my narcissistic ass." Twitter, 2 Sep 2013, 10:43 a.m. [deleted tweet]

American Psychiatric Association. Personality disorders. Diagnostic and Statistical Manual of Mental Disorders, Fifth Edition. Washington, DC: American Psychiatric Publishing, Inc; 2013.

Barlow, Helen. 2019. "Xavier Dolan on 'Matthias \& Maxime', 'IT 2', and Why He Wants to Act More." Collider. https://collider.com/xavier-dolan-interview-matthias-andmaxime-it-2/ Last accessed 04/04/2021

Benjamin, Jessica (2000). "The Oedipal Riddle". In Du Gay, Paul; Evans, Jessica; Redman, Peter (eds.). The Identity Reader. London: Sage. Quoted in Tyler, Imogen. "From 'The Me Decade' to 'The Me Millennium': The Cultural History of Narcissism." International Journal of Cultural Studies 10, no. 3 (September 2007): 343-63. https://doi.org/10.1177/1367877907080148

Bradshaw, Peter. 2017. "Xavier Dolan: 'If I didn't make movies, I would be a very angry man." The Guardian. https://www.theguardian.com/film/2017/feb/22/xavierdolan-if-i-didnt-make-movies-i-would-be-a-very-angry-man Last accessed 04/04/2021

Clark, Ashley. 2019. "The films defending the demonised millennial generation." BBC. https://www.bbc.com/culture/ article/20190718-the-films-defending-the-demonisedmillennial-generation Last accessed 04/04/2021

Dimock, Michael. 2019. "Defining generations: Where Millennials end and Generation Z begins." Pew Research Center. https://www.pewresearch.org/facttank/2019/01/17/where-millennials-end-and-generation-zbegins/ Last accessed 04/04/2021

Freud, Sigmund. 1914. "On narcissism: An Introduction." In The Standard Edition of the Complete Works of Sigmund Freud, 67-102. (1957) ed. Vol. 14. N.p.: Standard Edition.

Gabbard, Glen O. 1999. "The Cinematic Psychiatrist." Psychiatric Times 16, no. 7 (July). https://www. psychiatrictimes.com/view/cinematic-psychiatrist. Last accessed 04/04/2021

Gabbard, Glen O., and Krin Gabbard. 1999. Psychiatry and the Cinema. N.p.: American Psychiatric Pub.

Giesbrecht, Harvey, and Charles Levin. 2012. Art in the Offertorium: "Narcissism, Psychoanalysis, and Cultural Metaphysics". Leiden, The Netherlands:: BRILL.

Gilbey, Ryan. 2019. "You're so vain! The phenomenon of the self-loving actor-director." The Guardian. https:// www.theguardian.com/film/2019/jan/25/youre-so-vainthe-phenomenon-of-the-self-loving-actor-director Last accessed 04/04/2021

Goncalo, Jack, Francis Flynn, and Sharon Kim. 2010. "From a mirage to an oasis: Narcissism, perceived creativity, and creative performance." Cornell University. https://ecommons.cornell.edu/handle/1813/75580

Higgins, Bill. 2018. "Hollywood Flashback: Xavier Dolan Wowed With 'I Killed My Mother' in 2009." The Hollywood Reporter.https://www.hollywoodreporter.com/news/ hollywood-flashback-xavier-dolan-wowed-i-killed-mymother-2009-1141392 Last accessed 04/04/2021

Hirschberg, Lynn. 1997. "The Two Hollywoods: The Directors; Woody Allen; Martin Scorsese." The New York Times Magazine, November 16, 1997, 91. https://www. nytimes.com/1997/11/16/magazine/the-two-hollywoodsthe-directors-woody-allen-martin-scorsese.html Last accessed 04/04/2021

Kiang, Jessica. 2016. "Cannes Review: Xavier Dolan's Shrill, Shrieking Drama 'It's Only The End Of The World." The Playlist. http://theplaylist.net/cannes-review-xavierdolans-end-world-lea-seydoux-marion-cotillard-vincent- cassel-20160518 Last accessed 04/04/2021

Lafontaine, Andrée, ed. 2019. ReFocus: The Films of Xavier Dolan. N.p.: Edinburgh University Press.

Lyttelton, Oliver. 2014. "10 Great Self-Absorbed, Narcissistic Movie Assholes." IndieWire. https://www. indiewire.com/feature/10-great-self-absorbed-narcissisticmovie-assholes-271004/ Last accessed 04/04/2021

McGovern, Joe. 2015. "Meet Xavier Dolan, cinema's hottest enfant terrible." Entertainment Weekly. https:// ew.com/article/2015/08/11/xavier-dolan-tom-at-the-farm/ Last accessed 04/04/2021

Merriam-Webster.com Dictionary, s.v. "narcissist," accessed April 5, 2021, http://www.merriam-webster.com/ dictionary/narcissist

Mesley, Wendy. 2014. "Xavier Dolan calls Orson Welles 'a late bloomer.'" CBC. https://www.cbc.ca/news/ entertainment/xavier-dolan-calls-orson-welles-a-latebloomer-1.2786824 Last accessed 04/04/2021

Milstead, Kristen. 2018. "Watch These Movies About Narcissists." Fairy Tale Shadows. https://fairytaleshadows. com/thirteen-films-about-narcissists-what-to-showsomeone-to-help-them-get-it/ Last accessed 04/04/2021

O'Falt, Chris. 2016. "Xavier Dolan Is Going To Focus On Acting, Even If It Slows Down His Directing Efforts." IndieWire.https://www.indiewire.com/2016/05/xavierdolan-is-going-to-focus-on-acting-even-if-it-slows-downhis-directing-efforts-289104/ Last accessed 04/04/2021

Pinsky, Drew, and S. M. Young. 2009. The Mirror Effect: How Celebrity Narcissism Is Seducing America. N.p.: Harper Collins.

Remes, Olivia. 2016. "Why are we becoming so narcissistic? Here's the science." The Conversation. https://theconversation.com/why-are-we-becoming-sonarcissistic-heres-the-science-55773 Last accessed 01/11/2020

Rhodewalt, Frederick. 2020. "Narcissism." Encyclopedia Britannica. https://www.britannica.com/science/narcissism Last accessed 04/04/2021

Rooney, David. 2013. "Tom at the Farm: Venice Review." The Hollywood Reporter. https://www.hollywoodreporter. com/review/tom-at-farm-venice-review-619296 Last accessed 04/04/2021

Rose, Steve. 2019. "We've gone through a lot of trauma': why millennial stories are saving Hollywood." The Guardian. https://www.theguardian.com/film/2019/jul/20/ weve-gone-through-a-lot-of-trauma-why-millennial-storiesare-saving-hollywood Last accessed 04/04/2021

Seymour, Tom. 2015. "Xavier Dolan: 'I just want to express myself - like Madonna." The Guardian

Stein, Joel. 2013. "Millennials: The Me Me Me Generation." Time. https://time.com/247/millennials-theme-me-me-generation/ Last accessed 01/11/2020

Strombo. "Xavier Dolan On George Stroumboulopoulos Tonight: INTERVIEW." YouTube, YouTube, 30 Sept. 2013, www.youtube.com/watch?v=re-VqYe05hA Last accessed 04/04/2021

Young, Mark S., and Drew Pinsky. 2006. "Narcissism and celebrity." Journal of Research in Personality 40 (5): 463 - 471. 0092-6566.

Zhou, Yi. 2017. "Narcissism and the Art Market Performance." The European Journal of Finance, 23 (13). DOI/10.1080/1351847X.2016.1151804. 


\section{Filmography}

American Psycho (2000). Directed by Mary Harron., USA and Canada

Annie Hall (1977). Directed by Woody Allen., USA

Catch Me If You Can (2002). Directed by Steven Spielberg., USA and Canada

Citizen Kane (1941). Directed by Orson Welles., USA

Contempt (1963). Directed by Jean-Luc Godard.,

France and Italy

Deconstructing Harry (1997). Directed by Woody Allen., USA

Dr. Dippy's Sanitarium (1906). Shot by G.W. Bitzer., USA

Gone Girl (2014)., Directed by David Fincher., USA

Heartbeats (2010). Directed by Xavier Dolan., Canada

I Killed My Mother (2009). Directed by Xavier Dolan.,

Canada

It's Only the End of the World (2016). Directed by Xavier

Dolan., Canada and France

Laurence Anyways (2012). Directed by Xavier Dolan.,

Canada and France

Matthias and Maxime (2019). Directed by Xavier Dolan.,

Canada and France

Mean Girls (2004). Directed by Mark Waters., USA and

Canada

Mommy (2014). Directed by Xavier Dolan., Canada

The Bling Ring (2013). Directed by Sofia Coppola.,

USA, UK, France, Germany, Japan

The Death and Life of John F. Donovan (2018). Directed

by Xavier Dolan., Canada and UK

The Life Aquatic with Steve Zissou (2004). Directed by Wes Anderson., USA

The Social Network (2010). Directed by David Fincher., USA

The Talented Mr. Ripley (1999). Directed by Anthony Minghella., USA

The Wolf of Wall Street (2013). Directed by Martin Scorsese., USA

Tom at the Farm (2013). Directed by Xavier Dolan.,

France and Canada 